\title{
SISTEMA DELIBERATIVO, FORMAS DE CONEXÃO E INCLUSÃO POLÍTICA Alcance teórico e prático
}

\section{Claudia Feres Faria}

Universidade Federal de Minas Gerais (UFMG), Belo Horizonte - MG, Brasil. E-mail: claudia.feres.faria@gmail.com

DOI: $10.17666 / 329502 / 2017$

\section{Introdução}

A ideia de sistema deliberativo emerge a partir de um profícuo debate entre estudiosos da deliberação, preocupados com a expansão da prática deliberativa de espaços isolados, muitas vezes sem impactos efetivos, para a sociedade como um todo (Parkinson, 2006; Chambers, 2009). Diante dos desafios inclusivos postos às práticas deliberativas baseadas exclusivamente na razão comunicativa e nas relaçóes face a face, a teoria deliberativa passa por mudanças, alcançando, após muitas controvérsias, a ideia de sistema deliberativo (Mansbridge e Parkinson, 2012).

A ideia busca romper o insulamento da prática deliberativa em "enclaves" políticos por meio de uma "arquitetura" que prevê a interação entre múltiplas esferas e instituiçóes e diferentes formas

Artigo recebido em 8/4/2016

Aprovado em 17/2/2017 de comunicação que não somente aquelas baseadas na troca racional de argumentos.

Acredita-se que tal ideia apresenta vários méritos: permite estender no tempo e no espaço as práticas deliberativas, rompendo com o seu insulamento; permite coordenar um conjunto diferenciado de formas discursivas e vincular, de forma alternativa, a formação da opinião pública, as inovações democráticas e/ou os minipúblicos e as arenas decisórias, aumentando, assim, as chances de inclusão política (Elstub e McLaverty, 2013).

Desde o modelo "centro-periferia" de democracia deliberativa, elaborado por Habermas, os problemas relativos à legitimidade das decisóes vinculantes constituem preocupação desse campo. Recusando a eleição como a única base legítima das decisóes, o modelo proposto pelo autor defende a existência de uma esfera pública densa e porosa, coordenada pela ação comunicativa, pela qual a vontade e a opinião pública são gestadas via participa- 
ção e argumentação e transmitidas para os centros decisórios via fluxos comunicativos (Habermas, 1996). De lá pra cá, os debates em torno dessa ideia se adensaram, e os resultados das pesquisas empíricas empreendidas promoveram diferentes impactos na ideia original e na teoria em geral.

O objetivo deste artigo é duplo: analisar esse percurso, suas motivaçóes e seus desdobramentos até chegar à ideia de sistema deliberativo, e propor formas de operacionalizá-la tal como aparece em seu último giro. Faremos isso de acordo com os seguintes passos: na primeira seção, buscaremos situar o contexto e as motivaçóes para o surgimento da ideia de sistema. $\mathrm{Na}$ segunda, analisaremos três diferentes propostas de sistema deliberativo. $\mathrm{Na}$ terceira, exploraremos os constrangimentos levantados à operacionalização da ideia, assim como formas de superá-los por meio da análise de três conectores: comunidades e coalisóes políticas, representação dos atores e de temas, e os desenhos institucionais que balizam as interações no interior e entre as diferentes arenas em que essas comunidades e coalizóes atuam. Na quarta, algumas considerações finais serão apresentadas.

\section{Sistema deliberativo: contexto e motivaçóes}

A controvérsia em torno do conceito de razão pública marca o giro na teoria democrática no geral e na teoria deliberativa em particular. As contribuiçôes de Habermas (1984; 1997), dentre outros, ${ }^{1}$ à teoria democrática estão inteiramente assentadas na defesa das trocas argumentativas racionais como base para se alcançar decisóes políticas legítimas. ${ }^{2}$ Tais trocas ocorrem sempre que visóes de mundo diferentes estiverem em jogo, sejam elas morais, éticas e/ou pragmáticas. A solução para os conflitos que impulsionam o debate público regido por pretensóes de validade diferentes acontece por meio do consenso. Visóes de mundo diferentes, através das trocas argumentativas, serão transformadas e o consenso alcançado. A decisão vai requerer, portanto, que os debatedores, iguais em suas capacidades argumentativas, alcancem um ponto de vista comum que guiará as decisóes tomadas em cada domínio da vida. A falha nesse processo apontará sempre a seletividade das partes e a tendência de elas favorecerem comunicaçóes "sistematicamente distorcidas”, que geram decisóes passíveis de críticas por serem alcançadas sem o consentimento esclarecido dos atores/atrizes que afetam.

A "primeira geração" de estudos sobre a democracia deliberativa, da qual Habermas é um dos maiores expoentes, apostou, portanto, na ideia de uma razão pública universal como ponto de partida para a teoria em questáo, marcando aquilo que se convencionou chamar de "o primeiro giro" na teoria democrática. ${ }^{3}$

$\mathrm{O}$ acerto de contas com os problemas derivados da complexidade social - pluralismo cultural, étnico e a persistente desigualdade social - possibilitou a emergência de uma segunda geração de estudos em torno desse campo, configurando "o segundo giro" na democracia deliberativa.

De um modo geral, essa geração reconhece os limites da ideia de razão pública unitária para conformar e transformar as preferências e as visóes de mundo, bem como para alcançar o bem comum via a formação de consensos abrangentes. Passam a propor, assim, formas menos exigentes tanto de argumentação quanto da solução para sua troca. O consenso cede lugar a compromissos alcançados com base em formas plurais de comunicação e na formação de acordos parciais e provisórios entre maiorias (Bohman, 2000; Dryzek, 2000).

Parte dessa mudança deve-se ao "diálogo" com diferentes tradições do pensamento político contemporâneo, principalmente com agonistas e democratas da diferença ${ }^{4}$ que levantaram sérias críticas aos postulados contidos na formulação da primeira geraçáo. Civilidade, argumentos respeitosos, razão pública unitária e consenso são vistos como formas de ação indesejáveis que escamoteiam o conflito e a paixão, e reificam posiçóes de grupos subalternos. Por isso, esse campo - autodenominado democrata radical - aposta em uma versão mais "agonista" da política e da democracia.

Mouffe (2000a; 2000b), por exemplo, uma das principais expoentes do "agonismo democrático", acusa a primeira geração de deliberacionistas de ser incapaz de reconhecer a dimensão antagônica da política e propóe um modelo de democracia totalmente assentado na dimensão conflitiva. Relaçóes sociais e políticas são, nesse modelo, sempre mar- 
cadas pela disputa entre forças políticas antagônicas que se estabilizam quando um dos lados torna-se provisoriamente hegemônico. Procedimentos e decisóes derivados do reconhecimento dessa dimensão conflitiva da política regulam tais disputas e assumem a forma de acordos temporários, por serem frutos do antagonismo gerado pela relação nós e eles. $\mathrm{O}$ reconhecimento do grupo hegemônico deriva do acordo alcançado temporariamente com base em regras que asseguram a possibilidade do desafio permanente da hegemonia alcançada. A incerteza, mais que o medo e menos que convicçôes compartilhadas, torna-se a mola propulsora para adesão aos valores e às regras democráticas.

A luta para assumir um papel hegemônico via contestaçáo ganha centralidade, tornando-se mais um fim do que um instrumento para clarear posiçôes e acordar questóes e regras (Bächtiger et al., 2010). Desconsidera-se, assim, o fato de que a dinâmica discursiva enseja um processo de aprendizado das formas, das condições e do conteúdo da disputa que a ênfase somente na luta pela hegemonia obscurece.

De qualquer forma, o diálogo estabelecido entre esses dois campos resulta, segundo Gürsözlü (2009), em diferentes posições, que vão desde a negação da prática agonista até a tentativa de acomodá-la ao modelo deliberativo. A terceira e quarta geraçóes de estudos deliberativos se enquadram nessa segunda alternativa. Segundo Dryzek e Niemeyer (2010a), o modelo deliberativo, mesmo estando mais interessado na produçáo de resultados coletivos via trocas argumentativas, não desconsidera a importância da contestação e das diferentes formas de expressá-la, mas a acomoda em uma abordagem que se pretende sequencial (Neblo, 2005; Goodin, 2008) ou sistêmica (Mansbridge e Parkison, 2012).

Nessas novas versões, o tipo de relação estabelecido entre grupos e espaços, bem como a forma de coordená-la não é mais determinado a priori. Formas nomológicas ou dialógicas de coordenação da ação passam a ser determinadas pelo tipo de política em questão e pelo contexto institucional que as abrigam (Holzinger, 2005). O terceiro "giro" na teoria é impulsionado, portanto, pelos estudos empíricos e suas preocupaçóes em analisar contextos, temas e regras mais propícios à institucionalização da deliberação democrática. ${ }^{5}$ Para isso, um conjun- to de inciativas práticas passa a ser testado isoladamente aqui e alhures. Exemplos importantes são as análise dos minipúblicos, dos conselhos de políticas, dos orçamentos participativos, das assembleias de cidadãos, das comissóes parlamentares, além de análises vinculadas à internet e a outros meios.

A proliferação de estudos empíricos se, por um lado, ajudou a precisar as condiçôes e as variáveis que promovem tal prática no interior desses espaços, trouxe, por outro lado, novos desafios à teoria. Um dos problemas emergentes passou a ser a necessidade de ampliação dessas práticas e de seus impactos para a sociedade em geral e para a democracia como um todo. Nos termos de Pateman (2011), seria necessário romper com o insulamento dessas práticas em arenas estruturadas para tal. Para que a deliberação inclua todas as pessoas afetadas, promova a mudança nas preferências e ainda influencie a vida delas, as condiçôes favoráveis nos e dos minipúblicos devem ser replicadas para toda a sociedade.

A ideia de sistema visa oferecer uma resposta para esse outro problema uma vez que propóe diferentes arenas, em diferentes escalas, coordenadas horizontal e verticalmente por padróes plurais de comunicaçáo. Junto ao argumento referente à escala vem também a defesa de definiçóes cada vez mais frouxas de deliberação, como, por exemplo, a "fala cotidiana", que passa a figurar como um tipo "estendido" de deliberação funcionando como input para a operacionalização do sistema como um todo (Mansbridge, 2007; Jacobs, et al., 2009; Chambers, 2009).

Esse giro só exacerba algo já presente na mudança da primeira para a segunda geração, qual seja, o distanciamento paulatino dos pressupostos fundantes da teoria deliberativa, notadamente a ideia de razão pública universal. Às evidências empíricas - em diferentes espaços e contextos sociais, que apontam a prática deliberativa como um tipo de ação exigente, de difícil operacionalização -, Habermas (2005) responde com a afirmação de que "idealizações fortes" são necessárias para fundamentar normativamente a crítica aos contextos nos quais o exercício da razão pública é obliterada.

Em que pese os contra-argumentos, é possível afirmar, seguindo a divisão geracional introduzida por Elstub (2010), que a quarta geração de estudos 
na área endossa cada vez mais a ideia de uma pluralidade de padróes discursivos buscando analisar a interação entre eles e seus impactos nas instituiçôes das sociedades complexas. Esse novo giro sistêmico é marcado, portanto, pela aceitaçáo de diferentes formas de comunicação e por preocupaçóes relativas às formas tanto de compatibilizá-las quanto de estendê-las no tempo.

Se a defesa da incorporação de novos padróes de comunicação parece conformar um "consenso" na teoria analisada, não está claro ainda quais são os critérios para diferenciá-los e julgá-los (Stneir, 2008; Faria, 2012; Owen e Smith, 2015), nem as formas de vincular o micro e o macro (Niemeyer, 2012; Mendonça, 2016). Abordagens teóricas e empíricas buscam responder essa questão de diferentes modos. ${ }^{6}$ Nas próximas seções deste artigo, além de discorrer sobre os modelos de sistema deliberativo e apresentar alguns dos seus limites, proporemos formas de lidar com o problema da escala e da compatibilização dos padróes de comunicação sem desconsiderar os limites aludidos. Para isso, discutiremos três conectores, quais sejam, comunidades e colisôes políticas, representação de temas e atores $^{7}$ e desenhos institucionais.

\section{Os modelos}

Como ressaltamos, o primeiro esboço da ideia de sistema no interior da teoria deliberativa aparece com o modelo "centro e periferia" elaborado por Habermas (1997) em seu livro Between facts and norms. Nesse modelo, o sistema é composto por uma esfera pública ampla e distinta dos subsistemas político e econômico. Enquanto os padróes de ação da esfera pública são coordenados pela razão comunicativa, as ações dos dois outros subsistemas são coordenadas predominantemente pela razão instrumental. A conexão entre essas distintas arenas ocorre por meio de fluxos comunicativos que partem da periferia e influenciam as decisóes do centro composto pelos subsistemas político e econômico.

A ideia de sistema elaborada por Mansbridge (2007) e Mansbridge et al. (2012) difere espacialmente e funcionalmente do modelo supracitado. Nessa segunda proposta não há separação rígida entre as arenas e nem entre formas de coordenação da ação. Padrôes monológicos e dialógicos de coordenação estão presentes em todos as arenas, sejam elas institucionais ou não.

Enquanto no modelo centro e periferia, a coordenação comunicativa está sempre sob risco, podendo ser "colonizada" pelas formas sistêmicas de coordenação de ação, no modelo sistêmico apresentado por Mansbridge et al. (2012), todas as formas de comunicação são, em princípio, funcionalmente adequadas para a sua operacionalização. Diferentes formas de ação, em diferentes espaços, cumprirão funções diferentes, servindo, na medida do possível, de inputs uns para os outros e para o sistema conformar uma visão crítica do todo. Assim, o sistema é, nessa versão, composto por "um conjunto de partes diferenciadas, mas interdependentes, com funçôes distribuídas e conectadas de forma a construir um todo complexo" (Idem, p. 13).

Essa ideia combina arenas formais de tomada de decisão e arenas informais de formulação de temas e problemas concernentes ao interesse público que devem operar conjuntamente na construção de decisóes legítimas. Diferentemente do modelo centro-periferia, que assume uma estratégia mais defensiva em relação as arenas institucionais, essa versão defende um envolvimento maior das mesmas no processo deliberativo como um todo. Nela, o Estado representa, por exemplo, mais um dentre os múltiplos atores envolvidos, mesmo sendo reconhecido como fonte última de decisão coletiva.

Tal como evidenciamos na primeira seção deste artigo, em ambos os modelos o conflito é um propulsor da relação entre as partes, embora sua solução não dependa exclusivamente da prática deliberativa. Formas de comunicação menos exigentes, como a fala cotidiana, a retórica e a barganha são também modos reconhecidos e legítimos de solução de problemas em situações de conflito.

Ao introduzir diferentes padrões discursivos, os autores do segundo modelo reservam à prática argumentativa as funçóes epistêmica e ética do sistema, o qual desempenha ainda outra função: a democrática.

A função epistêmica diz respeito à produção de opinióes, preferências e decisóes com base nos fatos e na lógica argumentativa. São resultados de consideraçóes substantivas por meio da troca de ra- 
zões. Porque os tópicos deliberados dizem respeito às questóes do interesse comum, as escolhas devem ser fundamentadas com base nas preferências e opiniôes discursivamente consideradas (Idem, p. 18). A função ética vincula-se à ideia do respeito mútuo entre os cidadãos, que pressupóe um tratamento igual entre os pares e a não dominação com base no aporte de recursos diferenciados. A presença de uma pluralidade de vozes, interesses e opinióes está vinculada à função democrática, que prescreve a inclusão de todas elas. Uma vez que o escopo e o conteúdo da deliberação são afetados por aqueles que participam do processo deliberativo, o sistema não pode excluir nenhum cidadão sem uma justificação que possa ser razoavelmente aceita por todos, incluídos e excluídos.

Para incluir todos os afetados, o sistema precisa promover e facilitar ativamente a igual oportunidade de participação. Isso ocorre por meio de diferentes formas de comunicação que vão desde o protesto até a negociação cooperativa (Idem, p. 19).

Segundo Mansbridge et al. (2012), a realização dessas três funçóes pode entrar em conflito no sistema e, por isso, uma "ecologia deliberativa" é sugerida para que se possa analisar como a deliberação democrática pode ser alcançada. Práticas concretas, inseridas em contextos concretos, passam a ser analisados com o objetivo de aferir o desempenho deliberativo do sistema como um todo. Isso não quer dizer que todas as partes se comportarão de forma a alcançar o ideal proposto. Faz parte da divisão de trabalho assumida náo avaliar o todo pelas partes, ou seja, pela fraqueza ou pela força deliberativa de cada parte isolada. Argumenta-se que aquilo que é visto como fraqueza deliberativa isoladamente pode, no entanto, contribuir positivamente para o sistema como um todo (Idem, p. 21).

Assim, decisões democráticas legítimas são alcançadas sempre que forem dialogicamente gestadas em um contexto de respeito mútuo entre os cidadãos e através de um processo inclusivo de escolha coletiva. Esse tipo de legitimidade pode facilitar a cooperação, que, por sua vez, promove a deliberação. No entanto, toda vez que esse círculo virtuoso se quebrar, formas monológicas de ação, como o protesto, podem contribuir para restaurar essa dinâmica. A denúncia da falta de publicidade ou da fraqueza da deliberação em cumprir suas promessas contribui para promover a deliberação no todo. A possibilidade da crítica e a reconstrução das bases argumentativas ensejam as bases para a retomada da prática deliberativa (Idem, pp. 31-32).

Uma terceira alternativa da ideia de sistema, morfologicamente similar ao modelo centro-periferia, é oferecida por Dryzek (2009; 2010), cuja proposta prevê duas partes inter-relacionadas: o espaço público e os espaços "empoderados". O primeiro é composto por diversos fóruns, reais e virtuais, movimentos e associaçóes. Tais fóruns são abertos à participação e a multiplicidade de temas, abarcando, assim, diversos pontos de vistas. Os espaços "empoderados" são aqueles responsáveis pela produção de decisóes coletivas. Eles podem ser representados tanto por estruturas mais formalizadas - Legislativo, Judiciário e Executivo - como por estruturas menos formalizadas -fóruns, conselhos e comitês. Ambos são avaliados mediante suas capacidades de incluir interesses e vozes relevantes (Dryzek, 2009, pp. 1385-1386).

Embora defenda o pluralismo discursivo de forma similar à proposta de Mansbridge et al. (2012) e diferente ao modelo centro-periferia, Dryzek (2009) chama atenção para os possíveis efeitos deletérios advindos do uso de algumas formas de comunicação. Se, por um lado, o uso dessas diferente formas é útil na "disputa" pelo entendimento dos atores, na conformação da opinião pública e na luta pelo poder, por outro, há que se atentar para os efeitos coercitivos e particularistas que muitas delas podem promover (Idem).

A ideia de contestação discursiva é uma resposta de Dryzek (2000) à crítica elaborada pelas democratas da diferença e agonistas ao padrão racionalizante e pretensamente imparcial produzido pela visão de deliberação da primeira geração de deliberativos. Ao mesmo tempo, como ressaltamos, o autor não endossa o uso de todas as formas de comunicação sem cautela. Para lidar com os possíveis efeitos perversos causados pela prática de algumas delas, Dryzek (2009) aposta no exercício da justificação pública como forma de reflexão e controle de seus usos. Ao fazer isso, ele desvincula a legitimidade da democracia tanto da regra da maioria quanto do embate permanente entre forças antagô- 
nicas, vinculando-a à capacidade de reflexão e justificação dos atores em diferentes partes do sistema. A decisão alcançada, sempre provisória, reflete uma dinâmica caracterizada não só pelo uso plural das formas de comunicação, mas também pela justificação pública para as suas diferentes escolhas.

\section{Limites teóricos e possibilidades empíricas}

Para acomodar problemas decorrentes de uma visão unitária de razão pública, bem como do insulamento de suas práticas em espaços que não conseguem impactar a democracia como um todo, a ideia de sistema tem sido aprimorada e novos modelos têm sido propostos. Se, por um lado, esse esforço mostra a vitalidade deste campo analítico, por outro, as propostas apresentadas trazem consigo limites que merecem atenção. Esta seção tem, portanto, um duplo objetivo: analisar alguns desses limites, notadamente aqueles referentes à ausência de formas claras de conexão que possibilitem estender a prática deliberativa no tempo e no espaço, além de propor, por meio da análise de três conectores comunidades e coalizóes políticas, representação de atores e temas e desenho institucional - formas de superar essa lacuna.

\section{Limites teóricos}

Importante mencionar que a proposta de sistema, principalmente a versão elaborada por Mansbridge et al. (2012), já contempla um conjunto de problemas que passam a ser, desde então, considerados analítica e empiricamente, configurando uma nova agenda na pesquisa sobre a democracia deliberativa (Elstub e McLaverty, 2013; Boswell, 2015; Owen e Smith, 2015; Mendonça, 2016).

Mansbridge et al. (2012) chamaram atenção para os problemas referentes à incapacidade das partes de impactarem umas as outras, permanecendo isoladas, bem como para aqueles derivados do desequilíbrio de poder entre as arenas no sistema, os quais fomentam relaçóes de dominação política em vez de as diminuírem e controlarem (Idem, p. 22).

Ao analisar a questão da transmissão no sistema, Boswell (2015) adverte, igualmente, sobre o perigo da captura do conteúdo das políticas por grupos com mais recursos que podem mudar a interpretação desse conteúdo ao transmitirem visóes parciais e autointeressadas, consequentemente reproduzindo e reforçando ainda mais as assimetrias de poder (Idem, p. 11) e compromentendo ainda os possiveis esforços inclusivos realizados nas arenas isoladas.

Lembremos que o objetivo de estender a prática deliberativa para múltiplas arenas e grupos, na mesma ou em diferentes escalas territoriais, tem a ver com as possibilidades de disseminação de práticas e informaçóes que consigam conter os riscos aludidos, alargando os possiveis impactos inclusivos produzidos em espaços isolados.

Assumindo que as formas de comunicação constituem meios para conectar grupos e espaços diferentes, o endosso do pluralismo discursivo tem a ver com a percepção de que práticas mais e menos deliberativas podem se combinar para promover açóes e políticas que minimizem as patologias apontadas. Entretanto, há sempre o perigo de que as práticas menos discursivas de interação se sobreponham e reforcem as estratégias de dominação.

Como lidar, então, com o isolamento das partes, com a reprodução de assimetrias decorrente da forma de transmissão entre espaços e grupos, e com a possível sobreposição das outras formas de comunicação sobre a prática deliberativa? Este artigo, para além de apontar os desdobramentos críticos desse último giro no interior dos estudos sobre democracia deliberativa, assume uma postura propositiva ao buscar diferentes possibilidades de conexão entre as partes no interior do sistema, pretendendo, na medida do possível, responder a alguns dos limites identificados.

\section{Possibilidades empiricas: conectores}

Atores: comunidades elou coalisôes políticas ${ }^{9}$

A ideia de usar o conceito de comunidades e coalisóes políticas como conector de um sistema deliberativo é inspirada no debate estabelecido entre os estudiosos de políticas públicas que, buscando compreender como elas são formuladas e alteradas, chamam atenção para as dinâmicas interativas que são estabelecidas por uma ampla gama de atores sociais e políticos. A ideia de grupos - comunidades e coali- 
zões - tem a vantagem de ir além do foco em um ator específico, valorizando as interaçóes estabelecidas entre atores socialmente diferentes que se mobilizam na defesa de determinadas questóes de relevância pública.

Uma breve descrição da literatura pode nos ajudar a responder questóes relativas a como se identificam, mobilizam, interagem, impactam a agenda e geram a mudança.

Heclo (1978, apud Stillman, 2000) chamou atenção, de forma seminal, para a interação entre diferentes atores na elaboração de uma agenda pública que vão além dos tradicionais representantes do Executivo, do Legislativo e dos grupos de interesse. $\mathrm{O}$ autor propôs incluir às análises desse processo uma vasta rede de pessoas que interage com o governo e busca influenciar e guiar suas atividades. Assim, ele introduziu a perspectiva das "redes temáticas" (issue networks), enfatizando o papel que ideias compartilhadas podem adquirir tanto para a formatação e para a compreensão de determinados problemas públicos quanto para as suas possíveis soluções.

Uma rede temática compreende, segundo Heclo (Idem), um número muito amplo de participantes articulados entre si, movidos por um compromisso intelectual e/ou moral com alguma questáo, com graus variados de envolvimento e de dependência uns dos outros. Não é possível determinar os limites da rede, mas é possível identificar uma movimentação constante dos participantes, fora e dentro dela. Para Heclo, as redes operam em muitos níveis, e os participantes, mais do que peritos, são ativistas políticos que conhecem como cada um percebe a questão que os aproxima, estando determinadas a moldar a política pública em questão. Ele também destaca a possibilidade de que essas redes gerem líderes, denominados "políticos de políticas" (policy politicians).

O trabalho de Heclo pode ser considerado uma primeira aproximação da operacionalização da ideia de sistema deliberativo, uma vez que propóe um conjunto de atores em torno da discussáo de uma agenda pública - a questão da inclusão - e a circulação dos mesmos ao longo de arenas diferenciadas - a questão da conexão.

Embora enfatize a importância da interação entre os atores e as motivaçóes para agrupá-los ideias e compromissos partilhados - Heclo não analisa os tipos de interaçóes entre eles. As contribuições de Fischer (2003), entre outros, podem preencher essa lacuna, como veremos adiante.

Assim como Heclo, John Kingdon (2003) buscou explicar o processo de definição da agenda governamental por meio de um modelo interativo que envolve diferentes fluxos - o de problemas, o de alternativas e o político - que eventualmente se conectam. Esses fluxos abarcam também uma gama de atores que constituem o que Kingdon (Idem, p. 117) denomina "comunidade de políticas" (policy community). Atores internos e externos ao governo que têm em comum o interesse por um problema de política interagem de forma contínua e consistente ao ponto de conhecerem as ideias, as propostas e as atividades uns dos outros.

A ideia de comunidade de políticas introduzida por Kingdon pressupóe, assim como a ideia de redes temáticas de Heclo, uma pluralidade de atores que se agrupam em torno de uma questão de interesse público e que circulam pelos diferentes níveis de um sistema buscando intervir nos ciclos das políticas. A conexão entre as partes é feita, nesse caso, pelos "empreendedores de políticas", ${ }^{10}$ que, segundo Kingdom, investem energia e tempo em processos de sensibilização dos atores governamentais, na defesa pública das ideias da comunidade e na mobilização e formação da opinião pública no sentido de influenciar as instituições.

A busca por explicaçôes sobre as mudanças nas políticas públicas levou Sabatier e Jenkins-Smith (1999) a enfocarem, igualmente, as relaçóes que se estabelecem entre diferentes atores de uma área ou setor. Os autores estabeleceram assim o modelo de coalizão de defesa, a qual corresponde a uma aliança de grupos políticos (que abarca diferentes atores) que compartilham interesses e ideias num subsistema de política pública, em contraponto a outras coalisões. As coalisóes competem entre si e exercem pressão para que suas crenças tornem propostas de políticas públicas e entrem na agenda governamental, o que depende da capacidade financeira, intelectual, política e institucional de que elas dispuserem.

As alteraçóes na agenda de políticas públicas resultam de mudanças nos padróes de interação entre as coalizóes no interior dos subsistemas de política, as quais são geradas, em maior medida, por 
eventos externos ao subsistema e, em menor, por mudanças em parâmetros relativamente estáveis. ${ }^{11}$

A literatura citada contribui para a discussão empreendida neste artigo ao introduzir a ideia de grupos, de coletivos que vinculam diferentes atores em diferentes espaços e tempos. Comunidades e/ou coalisóes formadas por um amplo conjunto de atores disputam a interpretação de temas de interesse comum e influenciam, mediante diferentes recursos, a agenda pública e/ou sua mudança.

Ao enfatizarem as comunidades e coalisóes formados com base em ideias, interesses e valores compartilhados, as abordagens mencionadas têm a vantagem de ampliar os limites do político ao aumentarem as chances de uma pluralidade de atores e atrizes participarem do processo de construção da agenda pública.

Reconhecendo os ganhos mencionados do ponto de vista da inclusão, mas buscando ir além da discussão empreendida, Hajer e Wagenaar (2003), Fischer (2003), entre outros, enfatizam a importância da argumentação como forma de coordenação das interaçóes nas e entre as comunidades. Os estudiosos destacam particularmente o papel dos argumentos na definição e justificação de um problema, na construção de alternativas e recomendações. Segundo Fischer (2003), os processos discursivos têm a capacidade de desenvolver e refinar as ideias que os identificam, construindo $e$ reconstruindo os problemas de políticas e suas possíveis soluções (Idem, p. 183).

Ao reconhecerem que tais processo são também marcados por relaçóes de poder, chamam atenção para o problema da inclusão (e exclusão) de conteúdos, da distribuição de responsabilidades e do emprego de estratégias discursivas específicas. Nesse sentido, argumentam a favor do pluralismo discursivo - histórias, narrativas, retórica, demonstrações - útil para chamar a atenção para uma situação problemática, estruturar as comunidades e formatar o problema. Quando e onde escolher tais estratégias dependerá tanto dos temas quanto dos contextos em que o problema estiver inserido. Assim, formas mais competitivas ou cooperativas, conflitivas ou consensuais de solucionar uma questão não são dadas a priori, mas avaliadas e justificadas com base nessa reflexão.
Tal dinâmica nos permite avançar o debate sobre estratégias para lidar com os conflitos dentro e entre comunidades e coalizóes. Como proposto pela terceira geração de estudiosos da deliberação, formas mais conflitivas ou consensuais de lidar com as diferenças podem ser definidas mediante variáveis concretas - por exemplo, os contextos em que ocorrem, os temas em debate e as regras que regem as relaçóes entre seus atores.

Antes, porém, de avaliarmos o impacto das regras na promoção das conexóes entre as partes do sistema, analisaremos como a representação de atores "empreendedores de políticas" (Kingdon, 2003) - e de temas podem nos ajudar a estender a ação dessas comunidades no tempo e no espaço.

\section{Representação de atores e temas}

Para romper com os enclaves e estender a deliberação, é necessário pensar como as comunidade e as coalizóes políticas circulam pelo sistema, ativando outros públicos e conectando as múltiplas arenas envolvidas. Este artigo aposta na representação de seus membros e nos temas que os agrupam. Temas e atores têm a capacidade de sensibilizar grupos e circular entre e nas diferentes arenas estendendo as ações das comunidades. Se as relaçóes face a face podem confinar atores e debates nesses espaços, sua representação pode ter o efeito de alargar essa relação, vinculando o micro e o macro.

A representação se constitui, portanto, com base na participação dos membros das comunidades nos diferentes espaços dos sistemas e por meio dos debates sobre os temas que lhes identificam. Qual representação?

A discussão realizada em torno do conceito de representação é ampla e altamente adjetivada - de interesses, perspectivas, causas, podendo ser eleitoral, descritiva, discursiva etc. Por isso, é importante advertir o leitor que não constitui objeto deste artigo uma balanço dessa literatura. Importa frisar, entretanto, que apesar do rico e controverso debate que o conceito promove, existe um ponto comum: a consciência da inevitabilidade da representação em contextos de grande escala e os limites da visão tradicional a respeito dela.

Como ressalta a literatura especializada, em sociedades que abrigam múltiplas "pretensóes de 
representação" (Saward, 2006), derivadas da pluralidade de grupos, de visóes, interesses e perspectivas existentes, não é possível considerar somente a representação eleitoral, assentada nas questóes territoriais e na autorização por meio do voto (Urbinatti e Warrin, 2008; Dryzek e Niemeyer, 2010b; Lavalle et al, 2006; Avritzer, 2008; Almeida, 2013).

Diante da complexificação assumida pela dinâmica representativa, passa a ser igualmente importante analisar as bases em que ocorre a relação entre representantes e representados nesta "nova" realidade. A ideia de um "relacionamento diferenciado" (Young, 2002) entre eles, baseado no reconhecimento e no julgamento público das ações dos representantes pode nos ajudar a mapear as suas possibilidades de vinculação. Nesse caso, a participação na e entre as distintas arenas é fundamental para produzir informação necessária para qualificar as práticas de ambos: representantes e representados.

O julgamento e o controle dos representantes podem ainda ser efetivados de várias formas que vão do voto até as manifestaçóes públicas, envolvendo "empreendedores visíveis e invisíveis da política” (Kingdon, 2003). Essa dinâmica tende a sofrer alteraçôes, interrupçóes e provavelmente até rupturas. Os debates em torno dos temas que circulam nas e entre as arenas são capazes de publicizar essas ameaças e construir, nem sempre de forma deliberativa, alternativas para a manutenção dessa dinâmica. Os possíveis “empreendedores” perpassarão as arenas carregando consigo fragmentos desse debate. Por certo não advogarão exatamente aquilo que foi gestado nelas, mas podem e devem justificar suas posiçóes alimentando, assim, o próprio processo representativo.

O desafio consiste, portanto, em manter e alimentar essa relação diferenciada para que ela não se feche. O uso de padróes discursivos variados, como a retórica, por exemplo, pode ajudar a não obliterar o processo.

Assim como os atores, acredita-se que os temas, ao promoverem a representação das ideias, opinióes e interesses debatidas nas e entre as comunidades, constituem elos de conexão entre eles. Ao debaterem e disputarem a interpretação de um tema, as comunidades, coalisóes e públicos são acionados, dando início a uma trama discursiva que pode per- passar por todas as arenas de um determinado sistema. É essa dinâmica que impulsiona a reflexão de opinióes, interesses e perspectivas ao longo do processo de constituição, aferição e mudança das vontades políticas nas e entre as comunidades e coalisóes. Se bem-sucedidos, tanto temas quanto "empreendedores" das comunidades e coalisões são capazes de impactar as arenas decisórias.

É a qualidade dessas relaçóes nas e entre as distintas arenas que responde pela legitimidade do sistema. Uma das formas possíveis de aferir tal qualidade se dará via a análise das regras que ordenam as arenas e as relaçóes entre elas. Por isso, eleger os desenhos institucionais, suas regras, como mais um indutor da conexão no sistema. Se elas impactam as prática dos demais conectores - das comunidades e coalisóes políticas e da representação destas e dos temas debatidos - também respondem pela dinâmica deliberativa de todo o sistema.

\section{Desenhos e regras institucionais}

As regras e os procedimentos serão capazes de estender a prática deliberativa, qualificando opinióes e percepçóes acerca de determinados problemas da nossa realidade? Serão capazes de alargar o escopo das comunidades e coalisóes políticas, incluindo novas vozes aos processos participativos e deliberativos? Como poderão promover a coordenação de diferentes formas de comunicação em diferentes espaços?

A variável institucional sempre assumiu centralidade nas discussóes sobre a operacionalização das inovaçóes democráticas. Diversos estudiosos insistem na importância do desenho para avaliar as possibilidades deliberativas, a extensão da participação, a qualidade da representação e a efetividade e justiça das suas decisões finais.

Pensados isoladamente, os desenhos das inovações têm sido analisados para mensurar (1) a quantidade e os vieses da participação, bem como (2) as formas de mobilizar e recrutar atores. Em ambos os caso, a discussão e as possíveis mudanças nas suas regras podem impactar positivamente os processos inclusivos promovidos por essas inovaçóes. Da mesma forma, (3) a reflexão e o controle sobre temas - em debates e nos contextos em que ocorrem - podem impulsionar formas mais dialó- 
gicas de discussão, disseminando informações que qualificarão o processo decisório nessas inovaçôes. Regras e procedimentos podem interferir também na (4) relação entre representante e suas bases afetando o controle público. Ao impactarem essas dinâmicas, os desenhos tornam-se importantes preditores da legitimidades das inovaçóes analisadas (Holzinger, 2005; Fung, 2006; Smith, 2009; Avritzer, 2008).

No Brasil, os estudos das instituiçóes participativas valorizam igualmente a variável institucional para avaliar, isolada ou comparativamente, seus desempenhos em termos de inclusão política, formas de comunicação, controle público e efetividade dos seus debates (Lüchmann, 2007; Faria e Ribeiro, 2010; Coelho, 2011. Não obstante, a preocupação com as variáveis que explicam as relaçôes entre elas e suas conexóes só muito recentemente tem merecido atenção dos estudiosos do tema (Faria et al., 2012; Teixeira et al., 2012; Pogrebinschi, 2013). Exemplos notáveis desse esforço dizem respeito às análises que promovem as conexóes entre arenas, como os Conselhos e as Conferências de Políticas Públicas, permitindo que a participação e a deliberação se expanda horizontal e verticalmente (Almeida e Cunha, 2016).

De um modo geral, os trabalhos supracitados analisam as regras relativas aos tipos de atores recrutados e selecionados para mensurar a inclusão, os temas, os contextos e as formas de debate para aferir as possibilidades de deliberação. Regras relativas à representação dos públicos e ao controle dos/ as representantes buscam analisar, nas diferentes escalas em que os sistemas de políticas operam, a qualidade da representação praticada.

Em todos esses casos, reconhece-se igualmente que, embora as regras apresentem a capacidade de predizer os comportamentos, elas não os substituem. Assim, as possibilidades de incluir novos atores ao debate, criar capacidades deliberativas e fomentar a deliberação - além, ainda, de controlar os perigos advindos das possíveis formas de dominaçáo no interior e na passagem de uma arena para outra - são questóes que precisam ser investigadas empiricamente, não só para identificar os limites das regras, mas também para propor mudanças nelas.

\section{Notas conclusivas}

As mudanças retratadas na teoria deliberativa decorrem, como buscamos mostrar, de um intenso diálogo no interior do campo, em particular, e com seus diferentes interlocutores na teoria democrática, em geral.

A ideia de sistema é uma consequência desses debates e configura a quarta onda de mudanças no campo. Ela pretende responder questóes importantes para que a prática deliberativa alcance um impacto inclusivo mais amplo nas democracias contemporâneas.

Como em qualquer pesquisa em desenvolvimento, várias lacunas foram encontradas na ideia proposta. Uma delas, o problema da conexão entre as partes do todo, foi aqui abordada por meio da análise de três conectores - comunidades e coalisóes políticas, representação de atores, atrizes e temas, e regras que conformam os desenhos institucionais das múltiplas arenas que compóem o sistema. A análise foi feita com o objetivo de promover a conexáo entre as arenas e estender a deliberação no tempo e espaço.

Assumindo que um das principais preocupações dessa proposta é a promoção da inclusão de atores e temas no debate e nas decisóes políticas vinculadas aos sitemas, além de analisar as possibilidades de conexão, o artigo também chamou atenção para um conjunto de limites que a proposta enseja.

Problemas decorrentes da incapacidade do sistema de lidar com as falhas em suas partes quando, por exemplo, o vínculo representativo entre elas se desconecta e a prática representativa nas e das comunidades se fecha, comprometem a representação dos interesses, opiniōes e perspectivas de atores, arenas e temas. Tais problemas levantam a questão já clássica de como recuperar o elo perdido e reativar as conexóes.

$\mathrm{Na}$ análise realizada, sugerimos que, na ausência de mecanismos tradiconais de controle sobre a 
prática do conector "representação de temas e comunidades", repertórios alternativos de ação - mobilizações, denúncia, retórica, boicote, entre outras - possam servir como mecanismos societários de controle. Ao chamarem atenção e denunciarem publicamente a exclusão e as arbitrariedades exercidas, podem ajudar reativar o debate e, quando possível, retomar a conexão interrompida.

Da mesma forma, a dominação de atores e de temas no interior do sistema, causada pelo desinteresse e/ou falta de motivação dos "empreendedores" para ouvir e considerar reflexivamente os argumentos e/ou opinióes dos outros atores, às expensas das regras e desenhos dos espaços em que estáo inseridos, constitui risco que compromete a capacidade do sistema de operar de forma inclusiva. Nesses casos, sugere-se que as partes do sistema com maior poder de arbitragem, como o Estado, por exemplo, atuem de forma a coibir tais práticas e restaurar a legitimidade do todo (Bohman, 2013).

Como apontamos no decorrer do artigo, os constargimentos analisados comprometem a operacionalização dos conectores e, consquentemente, do sistema como um todo. Lidar com eles requer, no entanto, mais pesquisas e análises no interior do campo deliberativo. Tais estudos têm, assim como aqueles que impulsionaram as geraçóes anteriores, uma dupla função: continuar a elaborar um diagnóstico crítico da capacidade do sistema de responder aos desafios colocados pela realidade em que a ideia está inserida e pensar formas discursivas alternativas para superá-los.

\section{Notas}

1 Outra referência importante é John Rawls (1997), que não será abordado neste artigo. Para a crítica de Habermas à interpretaçáo de Rawls sobre o conceito de razão pública, ver Habermas (1998).

2 Habermas faz parte de uma tradição de pensadores que vinculam as patologias da modernidade ao deficit de racionalidade social, o que explica o interesse dessa tradição no processo histórico de realização da razão (Honneth, 2009).

3 Para a divisão geracional na teoria deliberativa utilizada neste texto, ver Elstub, S, 2010. Para a ideia de giros na teoria democrática e na teoria deliberativa ver Dryzek (2010).

4 Para uma revisão das posiçóes de importantes autores que fazem parte destes campos ver Gürsölü, F. 2009; Mendonça, D., 2010, Szwako, J, 2009.

5 Coletâneas e estudos realizados como os de Fung e Wright (2003), Gastil e Levine (2005), Hendrix (2006), Rosenberg (2007), Warren e Pearse (2008) e Dryzek (2000).

6 Para muitos autores, a circulação de diferentes padrões e meios de comunicação como a deliberação, a barganha, a retórica e o voto servirão para vincular as diferentes esferas, ver Mansbridge (1999), Hendrix (2006), Goodin (2008), Chambers (2009) e Warren (2012). Outros autores propóem, nos moldes aqui apresentados, diferentes tipos de conexão; ver Mendonça (2016), Rezende e Cunha (2016) e Faria e Cunha (2014).

7 Agradeço à Isabela Loureiro e Lins por ter chamado minha atençáo para o tema em debate como um dos conectores das diversas arenas no sistema.

8 A colonização do mundo da vida ocorre sempre que a forma sistêmica de ação - a ação instrumental predomina e expulsa a forma comunicativa de ação, base para a integração social, dos lugares que ela não poderia ser substituída, ocasionando assim patologias como as perdas de sentido e liberdade.

9 A ideia de "comunidade de política" já foi desenvolvida em outros textos de nossa autoria (ver Faria e Cunha, 2014) e está sendo reproduzida aqui com pequenas diferenças. Ela também foi anteriormente mobilizada por Cortês, Silva, Réos e Barcelos (2009) na análise da relação de diferentes atores em uma arena específica da política de saúde, o Conselho Nacional de Saúde.

10 Kingdon (2003) identifica dois tipos de empreendedores de política: os visíveis, que são aqueles que recebem considerável atenção da imprensa e do público, e os invisíveis, que formam as comunidades nas quais as ideias são geradas. Como atores visíveis, o autor sugere o chefe do Executivo, os ministros, os atores do Legislativo, a mídia, os grupos de interesse e os partidos políticos. Como invisíveis, o autor identifica os burocratas, os analistas e os acadêmicos.

11 Limites metodológicos e teóricos da ideia de coalisóes de defesa podem ser identificadas no trabalho de Fis- 
cher (2003). Uma crítica importante para os objetivos deste artigo refere-se não mais ao escopo das coalisóes, que passa a ser mais inclusivo se comparado com o padrão elitista anterior de conceber a agenda politica, mas à não consideração da diferenciação dos atores. Para Fischer, as tensóes derivadas dessa diferenciação e de suas relaçóes no tempo têm impacto nos tipos de negociaçôes - cooperativo, competitivo, consensual ou conflitivo - que elas estáo dispostas a fazer e, consequentemente, nas formas como os resultados das políticas públicas são alcançados (Idem, pp. 101-102).

\section{BIBLIOGRAFIA}

ALMEIDA, Débora R. (2013), "A relaçâo contingente entre representação e legitimidade democrática sob a perspectiva da sociedade civil”. Revista Brasileira de Ciências Sociais, 28 (82): 45-66.

ALMEIDA, Débora R. \& CUNHA, Eleonora S. (2016), "Brazilian social assistance policy: an empirical test of the concept of deliberative systems". Critical Policy Studies, 10 (2): 2-21.

AVRITZER, Leonardo. (2008), "Instituições participativas e desenho institucional: algumas consideraçóes sobre a variação da participação no Brasil democrático”. Opiniáo Pública, 14 (1): 43-64.

BÄCHTIGER, André et al. (2010), "Disentangling diversity in deliberative democracy: competing theories, their blind spots and complementarities". Journal of Political Philosophy, 18 (1): 32-63.

BOHMAN, James. (1996), Public deliberation: pluralism, complexity and democracy. Cambridge (MA), MIT Press.

. (2012), "Representation in the deliberative system", in John Parkinson e Jane Mansbridge (orgs.), Deliberative systems, Cambridge (MA), MIT Press.

BOSWELL, John. (2015), "Scale along deliberation". Paper presented at the Workshop on Deliberative Systems: A Critical Engagement. Londres, Centre for the Study of Democracy (CSD)/University of Westminster. [mimeo]

CHAMBERS, Simone. (2009), "Rhetoric and the public sphere: has deliberative democracy abandoned mass democracy?". Political Theory, 37 (3): 323-350.

COELHO, Vera Shattan P. (2011), "Uma metodologia para a análise comparativa de processos participativos: pluralidade, deliberação, redes e política de saúde”, in Roberto Rocha C. Pires (org.), Efetividade das instituiçóes participativas no Brasil: estratégias de avaliação, vol. 7. Brasília, Ipea.

CORTÊS, Soraya V.; SILVA, Marcelo K.; RÉOS, Janete C. \& BARCELOS, Marcelo. (2009), "Conselho Nacional de Saúde: histórico, papel institucional e atores estatais e societais", in Soraya Côrtes (org.), Participação e saúde no Brasil, Rio de Janeiro, Fiocruz.

DRYZEK, John. (2000), Deliberative democracy and beyond. Oxford, Oxford University Press.

. (2009), "Democratization as deliberative capacity building". Comparative political studies, 42 (11): 1379-1402.

(ORG.). (2010), Foundations and frontiers of deliberative governace. Oxford, Oxford University Press.

DRYZEK, John \& NIEMEYER, Simon. (2010a), "Representation", in John Dryzek (org.), Foundations and frontiers of deliberative governace, Oxford, Oxford University Press.

. (2010b), "Pluralism and meta-consensus", in John Dryzek (org.), Foundations and frontiers of deliberative governace, Oxford, Oxford University Press.

ELSTUB, Stephen. (2010), "The third generation on deliberative democracy”. Political Studies Review, 8: 291-307.

ELSTUB, Stephen \& MCLAVERTY, Peter. (2013), "Ten issues for a deliberative system". APSA Conference. Chicago, 29 ago.-1 set. [mimeo.].

FARIA, Cláudia F. \& RIBEIRO, Uriella C. (2011), "Desenho institucional: variáveis relevantes e seus efeitos sobre o processo participativo", in Roberto Rocha C. Pires (org.), Efetividade das instituiçôes participativas no Brasil: estratégias de avaliação, vol. 7. Brasília, Ipea.

FARIA, Cláudia F. (2012), "Do ideal ao real: as consequências das mudanças conceituais na teoria deliberativa". Lua Nova, 87: 63-82.

FARIA, Cláudia F., SILVA, Viviane P. \& LINS, Isabella L. (2012), “Conferências de políticas 
públicas: um sistema integrado de participação e deliberação?". Revista Brasileira de Ciência Politica, 7: 249-284.

FARIA, Cláudia F. \& CUNHA, Eleonora S. M. (2014), "Formação de agenda na política de assistência social: o papel das conferências como um sistema integrado de participaçáo e deliberaçáo". Revista Democracia e Participação, 1 (1): 73-96.

FISCHER, Frank. (2003), Reframing public policy: discursive politics and deliberative practices. Oxford, Oxford University Press.

FUNG, Archon and WRIGHT, Erik Olin. (2003), Deepening democracy: Institutional innovations in empowered participatory governance. Londres, Verso.

FUNG, Archon. (2006), "Varieties of participation in complex governance". Public Administration Review, 66 (s1): 66-75.

GASTIL, John \& LEVINE, Peter (orgs.). (2005), The deliberative democracy handbook: strategies for effective civic engagement in the twenty-first century. San Francisco, Jossey-Bass.

GOODIN, Robert E. (2008), Innovating democracy: democratic theory and practice after the deliberative turn. Oxford, Oxford University Press.

GÜRSÖLÜ, Fuat. (2009), "Agonism and delibartion: recognizing the difference". Journal of Political Philosophy, 17 (3): 356-368.

GURZA LAVALLE, A., HOUTZAGER P. \& CASTELLO, G. (2006), "Representação política e organizaçóes civis: novas instâncias de mediaçấo e os desafios da legitimidade". Revista Brasileira de Ciências Sociais, 21 (60): 43-66.

HABERMAS, Jürgen. (1984), The theory of communicative action. Vol. I: Reason and the racionalization of society. Boston, Beacon.

. (1997), Between facts and norms. Londres, Polity Press.

. (1998), "Reconciliation through the public use of reason", in The inclusion of the other: studies in political theory, Cambrigde (MA), MIT Press.

. (2005), "Concluding comments on empirical approaches to deliberative politics". Acta Politica, 40 (3): 384-392.

. (2009), Europe: the faltering project. Londres, Polity Press.
HAJER, Maarten A. (1993), "Discourse coalitions and the institutionalization of practice: the case of acid rain in Great Britain", in Frank Fischer e John Forester (orgs.), The argumentative turn in policy analysis and planning, Durham/Londres, Duke University Press.

HAJER, Maarten A. \& WAGENAAR, Hendrik. (2003), Deliberative policy analysis: understanding governance in the network society. Cambridge (MA), Cambridge University Press.

HECLO, Hugh ([1978] 2000), "Issue networks and the executive establishment", in Richard Stillman (org.), Public administration: concepts and cases, Boston, Houghton Mifflin.

HENDRIKS, Carolyne. (2006), "Integrated deliberation: civil society's dual role in deliberative democracy". Political Studies, 54: 486-508.

HOLZINGER, Katharina. (2005), "Context or Conflict Types: which determines the selection of communication mode". Acta Politica, 40: 239-254.

HONNETH, Axel. (2009), Pathologies of reason: on legacy of crtical theory. Nova York, Columbia University Press.

JACOBS, Lawrence R.; COOK, Fay Lomax \& CARPINI, Michael X. Delli. (2009), Talking together: public deliberation and political participation in America. Chicago, University of Chicago Press.

KINGDON, John W. (2003), Agendas, alternatives, and public policies. Nova York, Longman.

LÜCHMANN, Lígia H. H. (2007), "A representação no interior das experiências de participaçáo". Lua Nova, 70: 139-170.

MANSBRIDGE, Jane. (2007), "Deliberative democracy or democratic deliberation?", in S. Rosenberg (org.), Deliberation, participation and democracy: can the people govern?, Londres, Palgrave Macmillan.

MANSBRIDGE, Jane \& PARKISON, John (orgs.). (2012), Deliberative systems. Oxford, Oxford University Press.

MENDONÇA, Daniel. (2010), "Teorizando o agonismo: crítica a um modelo incompleto". Revista Sociedade e Estado, 25 (3): 479-497.

MENDONÇA, Ricardo F. (2016), "Mitigating systemic dangers: the role of connectivity in- 
ducers in a deliberative system". Critical Policy Studies, 10 (2): 171-190.

MENDONÇA, Ricardo F. \& SELEN, Ercan A. (2015), "Deliberation and protest: strange bedfellows? Revealing the deliberative potential of 2013 protests in Turkey and Brazil". Policy Studies, 36 (3): 267-282.

MOUFFE, Chantal. (2000a), The democratic paradox. Londres, Verso.

. (2000B), "Deliberative democracy or agonistic pluralism”. Political Science Series, 72. Viena, Institute for Advaced Studies.

NEBLO, Michael. (2005), "Thinking through democracy: between the theory and practice of deliberative politics". Acta Politica, 40 (2): 169-181.

NIEMEYER, Simon. (2012), "From the minipublic to a deliberative system: is scaling up deliberation possible?". Deliberative Democracy in Action, 6 jun. Åbo/Turku, Åbo Akademi.

PARKINSON, John. (2006), Deliberating in the real world: problems of legitimacy in deliberative democracy. Oxford, Oxford University Press.

PATEMAN, Carole. (2012), "APSA presidential address: participatory democracy revisited". Perspectives on Politics, 10 (1): 7-19.

PIRES, Roberto R. C. \& VAZ, Alexander C. N. (2014), "Para além da participação: interfaces socioestatais no governo federal". Lua Nova, 93: 61-91.

POGREBINSCHI, Thamy (2013), "The squared circle of participatory democracy: scaling up deliberation to the national level". Critical Policy Studies, 7 (3): 219-241.

SABATIER, Paul A. \& JENKINS-SMITH, Hank C. (1999), "The advocacy coalition framework: an assessment", in Paul A. Sabatier (org.), Theories of the policy process. Boulder (CO), Westview Press.

SZWAKO, José. (2009), "É a diferença o novo pluralismo? As contribuições de Mouffe, Connolly e Young para o pluralismo crítico". Trabalho apresentado no $33^{\circ}$ Encontro Nacional da Anpocs [mimeo.].

OWEN, David \& SMITH, Graham (2015) "Deliberation, democracy and the systemic turn". Journal of Political Philosophy, 23 (2): 213-234.

RAWLS, John. (1997), Uma teoria da justiça. São Paulo, Martins Fontes.
ROSENBERG, Shawn W. (Ed.) (2007), Deliberation, participation and democracy. Londres, Palgrave Macmillan.

SAWARD, Michael. (2006), "The representative claim". Contemporary Political Theory, 5 (3): 297-318.

RAMOS, Alfredo P. \& FARIA, Cláudia F. (2013), "Las Conferencias de Políticas Públicas en Brasil: hacia un sistema integrado de participación y deliberación a nivel nacional". Revista Española de Ciencia Politica, 32: 41-61

SILVA, Eduardo M. \& RIBEIRO, Antônio C. A. (2016), "Sistemas deliberativos em perspectiva meso: a abordagem dos subsistemas aplicada aos conselhos de políticas públicas em Belo Horizonte". Opiniāo Pública, 22 (1): 167-193.

SMITH, Graham. (2009), Democratic innovations: designing institutions for citizen participation. Cambridge, Cambridge University Press.

STEINER, Jürg. (2008), "Concept stretching: The case of deliberation”. European Political Science, 7 (2):186-190.

TEIXEIRA, Ana Cláudia et al. (2012), "Arquitetura da participação no Brasil: uma leitura das representações políticas em espaços participativos nacionais". Texto para Discussäo, n. 1735 : 1-44, Ipea.

WARREN, Mark E. \& PEARSE, Hilary (orgs.). (2008), Designing deliberative democracy: the British Columbia citizens' assembly. Cambridge (MA), Cambridge University Press.

URBINATTI, Nadia \& WARREN, Mark E. (2008), "The concept of representation in contemporary democratic theory". Annual Review of Political Science, 11: 387-412.

YOUNG, Iris M. (2002), Inclusion and democracy. Oxford, Oxford University Press. 


\section{SISTEMA DELIBERATIVO, FORMAS DE CONEXÁO E INCLUSÁO POLÍTICA: ALCANCE TEÓRICO E PRÁTICO}

\section{Claudia Feres Faria}

Palavras-chave: Sistema deliberativo; $\mathrm{Pa}$ drốes comunicativos; Escala; Comunidades e coalizôes de atores; Representação e desenho institucional.

Este artigo tem como objetivo avaliar a ideia de "sistema deliberativo", considerada aqui como parte do esforço da teoria deliberativa em lidar com um conjunto de problemas relativos à coordenação de múltiplas formas de comunicação, à escala e à inclusão política. Além de contextualizar o surgimento da proposta sistêmica no interior da teoria deliberativa (1) e apresentar suas diferentes versôes (2), este artigo identifica alguns limites da ideia chamando atençáo particularmente para o problema das conexóes entre suas partes (3). Feito isso, o artigo oferece três possibilidades de conexão: comunidades e coalizóes políticas, representaçáo de atores e temas e desenho institucional (4) buscando analisá-los do ponto de vista tanto das potencialidades quanto dos limites apresentados.

\section{DELIBERATIVE SYSTEM, CONNECTIONS, AND POLITICAL INCLUSION: THEORETICAL AND PRACTICAL POSSIBILITIES}

\section{Claudia Feres Faria}

Keywords: Deliberative system; Communication patterns; Scale; Connectors.

This article evaluates the idea of "deliberative system", which is considered an attempt of the deliberative theory to offer some theoretical and practical answers to different constraints related to the deliberative practices in a complex world, characterized by cultural and ethnical pluralisms, and by social inequality. Solutions such as the pluralization of arenas and patterns of communication are introduced by the idea of the deliberative system. However, new limits have arisen that created new analytical challenges. This article responds one of them through three steps: first, the article contextualizes and analyzes the motivations that created the idea of the deliberative system. Second, the article discusses some limits of this idea with a special attention to the possibilities of connections between the arenas and the possibility of scaling up the deliberative practices. Third, the article analyses three connectors that may link different arenas and patterns of communication to deal with the analyzed limits.

\section{SYSTÈME DÉLIBÉRATIF, FORMES DE CONNEXION ET INCLUSION POLITIQUE : PORTÉE THÉORIQUE ET PRATIQUE}

\section{Claudia Feres Faria}

Mots-clés: Système délibératif; Modèles communicatifs; Échelle; Communautés et coalitions d'acteurs; Représentation et conception institutionnelle.

Cet article vise à évaluer l'idée du " système délibératif ", considéré ici comme faisant partie de l'effort de la théorie délibérative à aborder un ensemble de problèmes relatifs à la coordination de multiples formes de communication, de l'échelle et de l'inclusion politique. L'article contextualise non seulement l'émergence de proposition systémique au sein de la théorie délibérative (1) et présente ses différentes versions (2), mais il identifie certaines limites de l'idée en portant l'attention du lecteur sur le problème des connexions entre les parties (3). Ceci dit, l'article offre trois possibilités de connexion : communautés et coalitions politiques, représentation d'acteurs et des thèmes et la conception institutionnelle (4), tout en cherchant à les analyser du point de vue du potentiel et des limites présentées. 